\title{
¿Cómo funciona la mente clínica? \\ Una contribución a la comprensión de la subjetividad de los psicoterapeutas desde la perspectiva del psicoanálisis relacional
}

\author{
André Sassenfeld J. ${ }^{1}$ \\ Santiago de Chile
}

\begin{abstract}
Este trabajo busca contribuir a clarificar la naturaleza de los procesos psíquicos de un psicoterapeuta cuando se encuentra en sesión, en un modelo clínico que no se basa en una concepción técnica sino en una comprensión de la psicoterapia relacional como práctica. En ese contexto, este trabajo explora en particular el concepto de phronesis analítica y algunos elementos de una concomitante psicología de la incertidumbre.
\end{abstract}

Palabras clave: mente analítica; phronesis analítica; incertidumbre

This article seeks to contribute to the clarification of the nature of a psychotherapist's psychic processes while in session, in a clinical model that is not based on a technical conception but on an understanding of relational psychotherapy as practice. In that context, the concept of analytic phronesis and some elements of an associated psychology of uncertainty are explored.

Key Words: analytical mind; analytic phronesis; uncertainty English Title: How does the clinical mind work? A contribution to the understanding of the subjectivity of psychotherapists from the perspective of relational psychoanalysis

Cita bibliográfica / Reference citation:

Sassenfeld J., A. (2019). ¿Cómo funciona la mente clínica?. Una contribución a la comprensión de la subjetividad de los psicoterapeutas desde la perspectiva del psicoanálisis relacional. Clínica e Investigación Relacional, 13 (2): 328-364. [ISSN 1988-2939] [Recuperado de www.ceir.info ] DOI: $10.21110 / 19882939.2019 .130203$

\footnotetext{
${ }^{1}$ Psicoterapeuta analítico relacional y jungiano de adultos en práctica privada. Es miembro del directorio internacional de IARPP y del directorio de IARPP-Chile. Dirección de contacto: asassenfeld@gmail.com
} 
La inquietud respecto de cómo funciona la mente de los psicoterapeutas cuando trabajan es a mi parecer una interrogante fundamental tanto en relación con nuestra creciente comprensión de las complejidades inherentes a la situación analítica como respecto de la formación de los psicoterapeutas. Saber cómo funciona nuestra mente cuando trabajamos puede tanto ayudarnos a volvernos mejores terapeutas como ayudarnos a dirigir con mayor especificidad y efectividad la formación de los terapeutas que están aprendiendo a trabajar en términos clínicos. En la historia del psicoanálisis la temática esbozada aparece en un inicio en las recomendaciones de Sigmund Freud (1912) respecto de la atención libremente flotante -contraparte de la asociación libre del paciente- y se prolonga, con posterioridad, en las a estas alturas innumerables contribuciones teóricas y clínicas que se han ido acumulando en torno al concepto de contratransferencia.

La emergencia del psicoanálisis relacional a partir de la década de 1980 trajo consigo un importante cambio terminológico que es reflejo de significativas transformaciones filosóficas y socioculturales más amplias. La contratransferencia se ha convertido en la noción más abarcadora de la subjetividad del psicoterapeuta, que en el marco del psicoanálisis relacional se visualiza como estando en interacción con la subjetividad del paciente en procesos conscientes e inconscientes continuos de influencia mutua. Junto a esta basal implicación del psicoterapeuta en la relación con su paciente, la profunda redefinición disciplinaria que el movimiento relacional ha hecho del psicoanálisis como práctica (Orange, Atwood \& Stolorow, 1997; Sassenfeld, 2012a, 2016, 2019), desprendiéndose cada vez más de su definición tradicional como teoría y/o como técnica, ha conllevado por necesidad una revaluación del lugar que ocupa la subjetividad del terapeuta en el quehacer analítico ${ }^{1}$.

¿Por qué? Porque así como un modelo técnico del psicoanálisis va de la mano de la noción de un analista estándar (Mitchell, 1997) neutral, abstinente y anónimo cuya subjetividad se entiende como controlada o incluso como aislada respecto de la experiencia del paciente, la comprensión del psicoanálisis como práctica es indesligable del tipo de subjetividad que toda práctica requiere con tal de poder ser efectiva y exitosa. Donna Orange, George Atwood y Robert Stolorow (1997) hacen uso de la filosofía aristotélica para definir el psicoanálisis como práctica y, con ello, se apropian del concepto central que Aristóteles empleó con la finalidad de dar cuenta del tipo de subjetividad que un practicante precisa para ser capaz de hacer un buen trabajo: la noción griega de phronesis. Este trabajo básicamente intenta recurrir a este concepto para comprender la mente clínica y explora algunas de sus múltiples facetas. 


\section{La phronesis analítica como paradigma de la mente clínica}

¿Qué es, entonces, esta enigmática phronesis que define la subjetividad del psicoterapeuta en un marco relacional que entiende la psicoterapia como práctica? Las traducciones de la palabra griega original son múltiples y ayudan bastante a formarse una idea inicial de su campo de significados. Para algunos, se trata de una inteligencia práctica o incluso de sabiduría (Orange, 2010; Orange, Atwood \& Stolorow, 1997; Sassenfeld, 2016). Steven Stern (2017) escribe respecto de esta primera, compleja traducción:

La palabra común para esta complejidad subjetiva [que implica la phronesis] es sabiduría -un tipo especial de sabiduría analítica que cada terapeuta analítico desarrolla de forma única de acuerdo a su propia estética o idioma propio como analista, incluyendo su idioma a la hora de seleccionar, sintetizar y reinventar las teorías psicoanalíticas en la medida en la que improvisa en cada sesión con cada paciente (Gabbard \& Ogden, 2009). Por supuesto, la sabiduría analítica es inseparable de cualquier sabiduría que el analista ha derivado de su experiencia vital y experiencia clínica [...] (p. 30, cursivas del original)

Este primer acercamiento deja en evidencia que la mente clínica entendida desde la perspectiva del concepto de phronesis está conformada por una complejidad subjetiva que abarca la experiencia personal del terapeuta.

Es evidente que una aproximación en la cual se espera que el psicoterapeuta disponga de sabiduría es compleja desde varios puntos de vista. Para partir, ¿desarrollan las formaciones psicoterapéuticas sabiduría en sus estudiantes? ¿Es y puede ser ese en realidad su objetivo? Y, de ser así, ¿cómo puede implementarse tal objetivo? ¿Son sabios los buenos psicoterapeutas? De entrada, ¿quién es capaz de definir lo que quiere decir sabiduría? Así, incluyendo estas y adicionales preguntas difíciles de responder, lo primero frente a lo cual nos coloca el concepto griego de phronesis es frente a una abismante complejidad y frente a una complicación en términos de cómo definir lo que se requiere para ser psicoterapeuta -¿sabiduría?

En este sentido, se entiende la preferencia histórica por una concepción técnica del psicoanálisis (por ejemplo, Etchegoyen, 2002 [1986]) en la cual las complejidades inherentes a la subjetividad del psicoterapeuta no parecen jugar un papel fundamental. Esta concepción técnica incluso promueve una supuestamente posible neutralización de la subjetividad del terapeuta, que se ve reflejada en los conceptos clásicos de la neutralidad, abstinencia y anonimato analíticos. Una concepción técnica elimina complejidad, aunque sea de forma reduccionista, al establecer reglas claras respecto de lo bueno y malo, respecto de lo permitido y lo no permitido (Mitchell, 1997; Sassenfeld, 2016, 2019). Por otro lado, dado que la noción de técnica está originalmente ligada al uso de materiales y la producción de objetos y no al trato con seres humanos (Orange, Atwood \& Stolorow, 1997; 
Sassenfeld, 2012a, 2016, 2019), tiende a deshumanizar tanto la situación analítica como al terapeuta. En concordancia con ello, la subjetividad del terapeuta ha recibido en ocasiones denominaciones como función analítica, dispositivo analítico o .

En inglés, podría tal vez decirse que la phronesis es el know-how, un saber que es procesal y que, así, no está en primer lugar vinculado con determinados contenidos sino con un saber-hacer, un saber lidiar con cierto tipo de tareas y situaciones. Puede entenderse como la capacidad que ha desarrollado quien, teniendo suficiente talento, se ha dedicado a una determinada disciplina durante tanto tiempo, que otros pudieran considerar que "tiene experiencia", que es un experto, que conoce bien su quehacer. (No puedo dejar de destacar que, al igual que la noción de sabiduría, la noción de talento también tiene sus propias dificultades.) Tener experiencia significa haber practicado, haber tenido exposición directa a algo de forma reiterada o incluso sistemática. Cuando nos parece que alguien tiene experiencia, al margen de los aspectos cotidianos y repetidos de su quehacer, estamos implicando que esa persona será capaz, de modo al menos relativamente razonable, de manejar el amplio espectro de situaciones difíciles, inesperadas, inusuales y complejas que pueden y que tienden a surgir en toda práctica.

Más allá, la traducción histórica del término griego al latín por parte de los romanos, más cercana al español, es interesante: prudentia, esto es, prudencia, sensatez, tino, conceptos que insinúan una dimensión ética de la phronesis y que, por lo tanto, alinean el uso del concepto de la phronesis analítica con el denominado giro ético en el psicoanálisis contemporáneo (Drozek, 2019; Goodman \& Severson, 2016; Orange, 2011, 2016; Sassenfeld, 2016, 2019). Por otro lado, si el paradigma de la noción de práctica es el vivir mismo (Gadamer, 1960; Sassenfeld, 2016), la phronesis puede equipararse en cierto sentido a lo que los franceses han llamado el savoir vivre, el saber vivir, que aquí no solo involucra la capacidad de disfrute y placer, sino también y fundamentalmente la capacidad de tomar decisiones oportunas y ajustadas a la situación y el momento en el cual nos encontramos. Como puede percibirse, no es tan fácil dar cuenta de la phronesis en términos conceptuales, aunque es probable que el lector ya se haya comenzado a formar una cierta idea de lo que es.

Frente a este trasfondo más general en torno a la noción de phronesis, tal como he argumentado con detención en otro lugar (Sassenfeld, 2012a, 2016, 2019), específicamente la naturaleza hermenéutica del psicoanálisis lo convierte en una disciplina de carácter práctico (véanse, también, Orange, Atwood \& Stolorow, 1997 y Stern, 1997, 2015). Sin duda, la práctica clínica del psicoanálisis se nutre de forma continua de las diversas teorías analíticas y de sus múltiples desarrollos técnicos tanto históricos como 
contemporáneos. Sin embargo, en cuanto práctica la psicoterapia psicoanalítica exitosa está determinada en primer lugar por lo que Orange (2011) ha llamado phronesis analítica, esto es, lo que quizás podríamos denominar criterio analítico. A diferencia de la concepción técnica de la subjetividad del psicoterapeuta, la idea de criterio no puede más que estar vinculada con una persona que es criteriosa; ninguna regla técnica puede reemplazar a un sujeto, a un individuo o persona, que decide qué hacer en base a su propio criterio.

En el pensamiento de otros teóricos relacionales, la llamada reflexión-en-acción-que podemos asemejar sin mayores dificultades a la phronesis- viene efectivamente a reemplazar el racionalismo técnico y su implementación mecánica que han imperado durante muchas décadas en el psicoanálisis tradicional (Hoffman, 1998; Safran, 2012; Safran \& Muran, 2000; Stern, 2015). En palabras de Irwin Hoffman (1998), en el marco del racionalismo técnico no hay lugar para

el involucramiento subjetivo personal del analista, para los enredos emocionales parcialmente enceguecedores, para la unicidad de cada interacción, para la incertidumbre y la ambigüedad, para los sesgos culturales, para el azar, para la creatividad del analista, para las dimensiones morales de la elección y para la angustia existencial frente a la libertad y a la mortalidad. (p. xii)

En un marco analítico phronético, los aspectos enunciados por Hoffman no solo tienen un lugar de relevancia, sino que más bien pasan a conformar la esencia del trabajo psicoterapéutico. Su enumeración deja, además, en claro que la reflexión-en-acción es un concepto que entiende al psicoterapeuta como persona.

Orange (2011) entiende la phronesis analítica como una inteligencia práctica emocional que atañe a la vida que transcurre en los vínculos afectivos entre seres humanos y que se manifiesta en sus mundos subjetivos de experiencia con organizaciones características y particulares. Este punto es significativo; porque la profesión de psicoterapeuta ocupa un lugar destacado y a la vez ambiguo desde el punto de vista que estamos discutiendo. Un terapeuta no es sin más comparable a un político o un juez -cuyos ámbitos de acción para Aristóteles y Hans-Georg Gadamer respectivamente son prácticos por excelencia- debido a que su práctica no está circunscrita de la misma manera. Su práctica es sumergirse, comprender y facilitar la transformación de la vida afectiva y relacional de los seres humanos como tal, en medio de y a través de los vínculos afectivos. La política o la jurisprudencia son prácticas, pero más específicas y delimitadas en comparación con la psicoterapia. En este contexto, quizás se puede comprender mejor por qué la phronesis puede tener ligazón con la sabiduría. 
Para Sandra Buechler (2008), por consiguiente, la formación analítica puede entenderse como el proceso de nutrir la capacidad del futuro terapeuta de marcar una diferencia en la vida de sus futuros pacientes. A la circunstancia mencionada, a mi parecer, puede atribuirse la idea -y la fantasía- generalmente difundida respecto de que un psicoterapeuta se maneja en su vida personal mejor que otras personas. Karen Maroda (1998) comenta la siguiente anécdota respecto de su propia experiencia de análisis:

En la medida en la que mi análisis progresó, aprendí bastante sobre mí misma, sobre mi analista y sobre el proceso. No solo no estaba alcanzando la perfección, sino que descubrí que tenía muchos más problemas de lo que yo pensaba. Aún peor, descubrí que mi analista también tenía muchos problemas. No es que ella me los contaba. No lo hacía. Pero, tal como todos los pacientes hacen, empecé a percibir sus vulnerabilidades, sus fallas, sus conflictos. Y cuando la confronté con sus propios problemas, me encontré con una resistencia masiva. Ella también creía que se suponía que ella debía estar más sana que yo y más en control de lo que ocurría en nuestra relación. (p. 30)

Nuevamente queda en evidencia que el psicoanálisis relacional visualiza al terapeuta como persona, lo cual implica la pregunta por la mente clínica que ocupa mis reflexiones en este trabajo.

Las ideas de Buechler y Maroda desembocan en una temática compleja que al menos desde la obra clásica de Alice Miller (1979) hasta los libros editados hace pocos años por Steven Kuchuck (2014) y Sharon Klayman Farber (2017) ha interesado a los teóricos analíticos. Las publicaciones mencionadas han contribuido de modo importante a desmitificar la vida e historia personal de los terapeutas y el inevitable lugar de estas en la elección de la profesión y en el ejercicio de la práctica clínica cotidiana (véanse, también, DeYoung, 2015 [2003]; Hunter, 1994; y Sassenfeld, 2019). No cabe duda de que teóricos psicoanalíticos históricos que fueron capaces de reconocer algunas dimensiones básicas de esta problemática incluyen a Wilfred Bion (1957) y su idea de que el psicoanalista al igual que todo ser humano tiene una parte psicótica de la personalidad que siempre lo acompaña en la situación analítica, y a Heinrich Racker (1960), en cuyos importantes estudios precursores sobre la noción de contratransferencia destaca la idea de que el terapeuta nunca deja de tener una parte enferma en su personalidad.

En el contexto esbozado, Merton Gill (1994) reconoce que un analista no necesariamente tiene que ser un parangón de salud mental, pero sí enfatiza a mi parecer de modo oportuno que aún así "tendría que ser alguien que al menos sea un tanto más consciente de sí mismo que el analizado" (p. 104). Así, explicita que la phronesis analítica implica un significativo grado de auto-consciencia por parte del psicoterapeuta, que es un aspecto esencial de un desarrollo significativo de su capacidad de mentalización (Allen, 
Fonagy \& Bateman, 2008; Fonagy, Gergely, Jurist \& Target, 2002; Sassenfeld, 2012a). La salud/enfermedad psíquica del psicoterapeuta es una dimensión central de lo que Owen Renik (1993) hace ya un cuarto de siglo con tanta elocuencia llamó la irreductible subjetividad del analista y que con anterioridad Karen Horney (1987 [1952]) describió de la siguiente manera criticando la neutralidad analítica clásica: "quizás solo puedes ser un terapeuta si estás con todo lo que eres en lo que haces. Personalmente, no veo por qué es preferible para mí trabajar con un poco de mí misma si puedo trabajar conmigo entera" ( $p$. 31).

Ahora bien, desde la perspectiva del concepto de la phronesis analítica, la pregunta respecto de si es necesario que un psicoterapeuta tenga su propia vida mejor resuelta que su paciente para poder ayudarle de manera suficientemente buena no deja de ser una pregunta relevante y abierta. $Y$ volvemos a las mismas dificultades que trae consigo la idea de sabiduría: ¿qué quiere decir tener la propia vida resuelta? No me siento en posición de poder contestar estas interrogantes sin ambigüedades y matices. No obstante, sí cabe poner al descubierto que estas preguntas en ciertos sentidos han jugado un rol de relevancia en la historia del psicoanálisis y en la creciente estructuración de la formación analítica a partir de la década de 1920 en Berlín. Testigo de ello es el temprano y sostenido énfasis que Carl Gustav Jung y Freud colocaron en la necesidad de un análisis personal para poder ejercer como psicoanalista (véase, también, Ferenczi, 1949 [1933]) -condición que, dicho sea de paso, ninguno de ellos cumplió a no ser que se desee equiparar un auto-análisis con un psicoanálisis. También lo es la hoy en día cuestionable pero históricamente comprensible idea de Freud de que alguien "analizado" puede ser más "objetivo" que alguien que no lo está respecto de la realidad psíquica propia y ajena.

La concepción freudiana inicial respecto de las reacciones contratransferenciales como reacciones neuróticas del analista que distorsionan de modo indeseable su percepción y que por ende requieren análisis y/o auto-análisis es un ejemplo adicional de lo dicho. Jung (1943 [1942]) llegó a afirmar que ningún psicoterapeuta puede llevar a su paciente más lejos de lo que él o ella misma ha avanzado consigo o consiga misma en su desarrollo psíquico. Ambas ideas en conjunto encarnan una fundamental contradicción en torno a la temática de este artículo: mientras que Freud desea neutralizar la subjetividad del terapeuta, Jung coloca su pleno desarrollo en un primer plano. Después de Freud y Jung, Horney (1957) describió entre otras cosas la madurez como cualidad esencial del analista otro concepto que arroja relevantes interrogantes. ¿Qué quiere decir madurez y quién la define? Sin poder contestar con claridad las múltiples preguntas mencionadas, sí es necesario agregar un comentario respecto de la phronesis y respecto de la phronesis analítica en particular, comentario que atañe de modo inmediato a la formación de los 
psicoterapeutas. Si la phronesis, con relativa independencia de su definición específica, define la mente clínica, ¿cómo se puede desarrollar?

Gadamer, y con él Orange, destacan que en primer lugar ello ocurre a través de la experiencia directa; en otras palabras, la phronesis se desarrolla ejerciendo una determinada práctica (Sassenfeld, 2016). Este punto difícilmente requiere mayor aclaración ya que es evidente que alguien con las capacidades suficientes para llevar a cabo una determinada actividad, mientras más se dedica a esa actividad, mayor experiencia y destreza adquirirá a la hora de practicarla. En segundo lugar, el desarrollo de la phronesis puede tener lugar en cierta medida observando a quienes ejercen la práctica con phronesis y, con ello, aprendiendo de lo que hacen. No sorprende, en este sentido, que a la mayoría de los psicoterapeutas nos gusta ver trabajar o escuchar acerca de su trabajo clínico a terapeutas con mayor experiencia que admiramos, así como aprendemos muchísimo de nuestros terapeutas, supervisores y ciertos colegas. De modo interesante, Freud (1910) afirmó respecto del aprendizaje de la técnica psicoanalítica que esta "aún no puede ser aprendida en los libros [sino que] debe aprenderse de aquellos quienes ya son competentes en ella" (p. 140) -aunque su comentario de todos modos parece dejar abierta la posibilidad de que en algún momento sí será factible interiorizarse en la técnica psicoanalítica por medio de lecturas. Tal idea, en el marco del psicoanálisis relacional, en la actualidad no es aceptable ya que sigue buscando reducir el psicoanálisis a una concepción técnica en la cual la subjetividad analítica apenas ocupa lugar.

Después de Freud, Horney (1987 [1952]) por su parte enfatizó que, en realidad, la técnica analítica entendida como la forma concreta de trabajar clínicamente no podía enseñarse en seminarios y clases. Para ella, en la supervisión clínica en cambio era posible ayudar a un terapeuta a tratar con los problemas y desafíos específicos que un paciente particular le presenta, incluyendo la consideración de los asuntos personales del terapeuta que podían estar implicados en el tratamiento de un paciente particular. Más allá, a Horney le pareció que la práctica del psicoanálisis en el fondo "solo puede enseñarse en un grado limitado porque, en última instancia, la técnica depende de la libertad interior, la ingenuidad y los sentimientos intuitivos" (p. 17) -esto es, de la phronesis analítica, que como podemos percibir tan difícil resulta conceptualizar de modo satisfactorio a raíz de su complejidad. Horney subrayó que esos son componentes importantes de la técnica terapéutica efectiva que pueden ser estimulados y apoyados, pero que no pueden ser enseñados. Vale decir, probablemente restringida por la terminología imperante en su época, hizo uso del término técnica para hacer referencia a lo que aquí estamos llamando phronesis. En su opinión, los aspectos mencionados se expresan en términos concretos en 
habilidades como interpretar en el momento oportuno y de una manera oportuna o tener facilidad para aprehender el significado de los sueños del paciente.

Sea como sea, parece evidente que el desarrollo de la phronesis de un terapeuta solo puede producirse sobre la base de lo que yo llamaría un talento basal y que Orange (2011, 2016) ha caracterizado como vocación analítica. Una vez más, la concepción de una vocación analítica implica dificultades similares a los conceptos de sabiduría y talento que mencionamos con anterioridad. Estos conceptos traen aparejadas dificultades teóricas al menos en parte porque son conceptos que pudieran considerarse como "demasiado subjetivos", esto es, porque no son definibles al margen de un sujeto particular que expresa su opinión personal al respecto. Para quienes enseñan una determinada práctica, no obstante, con frecuencia estos conceptos -al margen de su característica "subjetividad"son utilizados en base a la propia experiencia como sujetos que han sido formados y que forman a otros, teniendo una significación auto-evidente en términos de la práctica misma. Desde ese punto de vista, pueden entenderse como conceptos que deben entenderse como phronéticos o basados en una práctica particular.

En ese marco, en cuanto destacados formadores de psicoterapeutas relacionales, Jeremy Safran y Christopher Muran (2000) señalan que la habilidad psicoterapéutica abarca aspectos creativos e intuitivos que son dificultosos de transmitir y enseñar. De nuevo, ¿cómo podríamos definir con claridad lo que son la creatividad y la intuición? Safran y Muran aseveran que diferentes investigaciones existentes acerca de la naturaleza de la expertise profesional en general, más allá del psicoanálisis, muestran que quienes dominan el campo de su quehacer práctico responden a situaciones relevantes de modo flexible, creativo y contextualmente sensible. A diferencia de los "novatos", que tienden a aplicar en parte debido a su inseguridad determinadas reglas a modo de "receta de cocina" como una implementación técnica, los expertos recurren a la ya mencionada reflexión-en-acción. ¿Es esto algo transmisible en términos de una formación clínica? De ser así, ¿cómo puede tener lugar tal transmisión y qué formas de enseñanza pueden tener éxito? Aún más interrogantes difíciles de responder.

A mi parecer, la noción de phronesis posibilita la forma adecuada de entender el conocido comentario de Hoffman (1998) respecto de que los analistas necesitan "tirar lejos el libreto" (throw away the book) con tal de encontrar suficiente espontaneidad al margen de las constricciones técnicas tradicionales. Por supuesto, el comentario de Hoffman es una reacción phronética frente a las restricciones de la técnica psicoanalítica clásica. No se trata, en ningún caso, de una invitación a la irreflexividad e impulsividad (véase, también, BCPSG, 2010). La reflexión-en-accion descrita por Safran y Muran (2000) involucra "tratar 
casos nuevos como únicos y construir teorías nuevas para encajarlos más que depender de las categorías de la teoría y técnica establecidas" (p. 4). Esto no quiere decir que las teorías y consideraciones técnicas con las que ya contamos sean irrelevantes, sino que estas son "elaboradas, refinadas y modificadas por medio de una 'conversación' en curso con la situación existente" (p. 4). Una aproximación como esta coloca, de hecho, un gran peso sobre la formación, supervisión clínica y psicoterapia personal, las instancias principales en las cuales la reflexión-en-acción puede en alguna medida desarrollarse y profundizarse.

En términos históricos, el psicoanálisis capturó ciertos aspectos de la phronesis analítica al emplear conceptos como intuición y tacto analíticos (Ferenczi, 1928; Reik, 1948; Kohut, 1977) -temáticas poco presentes de modo explícito en la obra del mismo Freud- y con posterioridad también en la idea del timing de las intervenciones terapéuticas. En la actualidad, es posible repensar el concepto clínico del timing en base al análisis fenomenológico del momento presente realizado por Daniel Stern (2004), que justamente viene a rescatar -en un marco que me parece phronético- la relevancia de una intervención oportuna, esto es, ajustada a la situación relacional existente en un momento dado irrepetible entre paciente y analista y del proceso analítico que co-construyen. El concepto de la intuición analítica ha resurgido en el discurso psicoanalítico contemporáneo incluyendo lo que hoy sabemos acerca de sus probables fundamentos neurobiológicos en el trabajo de Allan Schore (2012) -paradójicamente, ha resurgido en un mundo que gira en torno a la optimización constante de la efectividad y rapidez del trabajo que los psicoterapeutas realizan con sus pacientes.

Por otro lado, las múltiples alusiones recientes a la práctica del psicoanálisis como arte son, a mi parecer, también expresiones del reconocimiento del lugar central que ocupa la phronesis analítica a la hora de ejercer la psicoterapia (por ejemplo, Lichtenberg, 2005 y Schore, 2012; antecedentes pueden encontrarse en Fromm, 1974; Horney, 1987 [1952]; y Loewald, 1974). Joseph Lichtenberg (2005) indica:

Con arte me refiero a la habilidad del terapeuta -no solo la que lo convierte en un terapeuta eficiente, sino también la habilidad de ayudarles a sus pacientes de tal manera, que también se conviertan en pacientes eficientes. Con arte además me refiero a un actuar que toca la destreza y la creatividad y que se sustrae a la "técnica" de meras reglas y rituales. (p. 13)

Tal como ya he dicho, es evidente que la noción de la phronesis analítica no es fácil de definir y que su centralidad arroja numerosas interrogantes en relación con la formación de psicoterapeutas. Sin embargo, se trata de un problema en el cual no me adentraré con más 
detalle en este trabajo (véanse, por ejemplo, Berman, 2004; Kernberg, 1996; Safran \& Muran, 2000; y Wachtel, 2014).

Un aspecto constitutivo de la phronesis que aquí deseo subrayar en base a lo ya descrito es la forma que en ella adopta la toma de decisiones, una dimensión central de la práctica clínica. En cierto sentido, puede quizás incluso aseverarse que la phronesis está en buena medida constituida por un determinado tipo de toma de decisiones. Los psicoterapeutas literalmente tomamos decisiones segundo a segundo de cada sesión, algo que ocurre en toda práctica. Resuenan aquí las palabras de Jean-Paul Sartre, para quien el ser humano está condenado a elegir. Mientras que en la teoría y en la técnica la toma de decisiones recae básicamente sobre procedimientos que en buena medida pueden generalizarse y estandarizarse y que son externos al sujeto que decide (por ejemplo, los principios lógicos que rigen el pensamiento sistemático o los pasos que conducen al ensamblaje de un mueble), en el ámbito de toda práctica la toma de decisiones es indesligable de las características particulares que constituyen una situación específica e irrepetible en la cual uno se encuentra.

El contextualismo del psicoanálisis contemporáneo (Orange, Atwood \& Stolorow, 1997; Sassenfeld, 2016, 2019; Wachtel, 2014) implica que toda decisión clínica depende del momento en el cual se encuentra un proceso psicoterapéutico particular y es propia de una díada terapéutica específica. Howard Bacal y Lucyann Carlton (2011) han hecho referencia a ello como la especificidad del tratamiento psicoanalítico, una noción que en sus propias palabras se aleja de la supuesta universalidad de determinadas estructuras psicológicas y se enfoca en la especificidad propia de todo proceso analítico particular. Ya en 1998, Bacal había escrito con elocuencia respecto de su concepto de responsividad óptima por parte del analista, que guarda fundamentales vinculaciones con la noción de phronesis y tiene raíces significativas en el trabajo de Ferenczi, Michael Balint, Donald Winnicott y Franz Alexander:

El concepto de responsividad óptima descansa sobre una teoría de la especificidad terapéutica: que es la especificidad de la interacción entre un paciente particular y un terapeuta particular lo que será de ayuda. [...] El funcionamiento terapéutico con frecuencia constituye respuestas que son muy distintas de y que pueden abarcar mucho más que -y a veces mucho menos que- lo que nuestras teorías y nuestros profesores nos han contado que hacen. [...] Por ende, el concepto de responsividad óptima confiere legitimidad a los cambiantes énfasis sobre la actividad verbal y no-verbal, la intervención interpretativa -transferencial o reconstructiva- $u$ otros tipos de comportamientos, incluyendo el entonamiento empático, la confrontación, el apoyo, el reconocimiento, el compartir afectos y experiencias subjetivas (auto-revelación), la reserva, la validación o invalidación y la escenificación- todas las cuales juegan diversos papeles en la conducción efectiva de todo psicoanálisis y psicoterapia dinámica. (p. xii) 
Así, la phronesis analítica debe poder contar con una multiplicidad de alternativas aceptables de intervención. No puede restringir de modo arbitrario sus propias posibilidades de decisión y acción en base a ciertas teorías y compromisos ideológicos inflexibles porque su compromiso no es con el cumplimiento de ciertos estándares generales o ciertas ideas teóricas, sino con el abordaje de situaciones prácticas. En cuanto tales, se trata de situaciones que son únicas e irrepetibles para las cuales invariablemente hace falta una respuesta que encaje con la situación existente. En efecto, la responsividad óptima implica que "no debiera existir interdicción contra cualquier respuesta que pudiera ser óptima para el paciente a no ser que interfiera con el funcionamiento profesional del terapeuta o su tolerancia personal" (Bacal, 1998, p. xii). Así, Bacal aclara que su concepción debe ser entendida como inserta en la mutualidad del vínculo analítico. Representa un claro ejemplo precursor de lo que en este trabajo estoy llamando phronesis analítica.

El trabajo de Bacal y Carlton (2011) encaja de manera evidente en un marco psicoanalítico phronético. Afirman:

La teoría de la especificidad confiere sustancia a la concepción de que toda teoría de la psicoterapia y su metodología son potencialmente tanto "correctas" como "incorrectas"; pero que su utilidad depende de su relevancia para la unicidad del proceso en el cual individuos particulares están participando. [...] Con la teoría de la especificidad intentamos discernir la respuesta anticipada o deseada o necesitada; aun así, la teoría de la especificidad es única al afirmar a continuación que seguimos examinando si acaso la respuesta fue útil y alterar nuestra responsividad lo mejor que podemos. (pp. 10-11)

La noción de responsividad óptima y la noción de especificidad a la que dio lugar contrastan -valga la redundancia- específicamente con la asumida validez de "una universalidad de disposición mental que es intrínseca a toda la teoría psicoanalítica tradicional" (p. 11). Así, la mente clínica phronética es una mente diversa y compleja que no puede ser estandarizada o normada.

En otras palabras, aunque la noción de especificidad no implica en ningún caso descartar las teorías analíticas históricas y contemporáneas, sí subordina su utilidad a las necesidades del paciente en determinado momento de proceso analítico (véanse, también, Mitchell, 1993 y Sassenfeld, 2012a, 2016, 2019) y rechaza la posibilidad de validez universal de cualquier concepción psicoanalítica. En la subordinación de las teorías psicoanalíticas a las necesidades del paciente reaparece la dimensión ética de la phronesis: asume en términos clínicos que el valor mayor es el bienestar del paciente. Tal como Bacal y Carlton señalan, su trabajo se ha movilizado desde la universalidad de la mente entendida como determinada estructura (por ejemplo, ello, yo y super-yo) hacia la especificidad del proceso psicoterapéutico. Con ello, han cambiado el tipo de teoría que buscan formular. Se quieren 
acercar a visualizar la mente como proceso y la interacción entre mentes como algo único, impredecible y no replicable. Desde ese punto de vista, "no existen líneas directrices para la técnica ni manuales para comprender al paciente" (Bacal \& Carlton, 2011, p. 12). El analista necesita y no puede más que recurrir a otra cosa, que hemos estado llamando phronesis.

Aparte de Jung (1946 [1926]) y también Ferenczi, con quien siendo de Budapest él mismo tuvo contacto hasta emigrar a Estados Unidos, quizás uno de los primeros teóricos analíticos en subrayar una perspectiva como esta fue Alexander. Tan temprano como 1946, escribió acerca del principio de flexibilidad -que recuerda la denominada elasticidad de la técnica psicoanalítica a la cual Ferenczi (1928) se había referido- señalando:

Mientras el método psicoanalítico de tratamiento fue considerado un procedimiento único, el analista -fuera consciente de ello o no- seleccionaba sus pacientes para que encajaran con su técnica; solo algunos intentaron adaptar el procedimiento a la diversidad de casos con la que se encontraron. Tal estado de cosas está lejos de ser satisfactorio. En toda la medicina existen muy pocas instancias en las cuales la herramienta terapéutica está rígidamente fijada y se hace que los pacientes se conformen a ella. La solución lógica a los problemas de la terapia es más bien la inversa. No solo sus padecimientos difieren mucho, sino que los pacientes mismos presentan muchas diferencias físicas y psicológicas. En psicoterapia, como en toda terapia, el médico tiene que adaptar su técnica a las necesidades del paciente. (Alexander \& French, 1946, p. 25)

En el psicoanálisis interpersonal, Horney (1956) también expresó esta perspectiva planteando que la comprensión de cada paciente particular representa la base de toda técnica psicoanalítica.

Más allá de las evidentes prohibiciones generalmente también legales que enmarcan una relación terapéutica (sexualidad y abuso de poder), desde el punto de vista del psicoanálisis relacional no existen reglas universalmente válidas a la hora de llevar un proceso analítico y de lidiar con las innumerables situaciones emergentes que pueden surgir en él. En efecto, hasta el marco analítico es tratado con relativa flexibilidad y visualizado como fenómeno que adopta determinadas características dependiendo de la díada terapéutica particular que lo ponga en práctica (Atwood \& Stolorow, 1997; Bass, 2007; Hoffman, 1998; Lichtenberg, 2005; Lichtenberg, Lachmann \& Fosshage, 1996; Mitchell, 1993; Sassenfeld, 2012a, 2016, 2019; Stolorow, 2010; Tylim \& Harris, 2018) -sin desconocerse que por cierto existen algunas condiciones mínimas que posibilitan un proceso analítico. Tal como señalan Bacal y Carlton (2011): 
La teoría de la especificidad, en congruencia con otras teorías de proceso, reconoce que no podemos saber a priori cómo cualquier respuesta particular o interacción diádica afectará al paciente, al analista o su relación, pero lo que sí sabemos es que lo que constituye la acción terapéutica también es específico; esto es, lo que podría ser terapéutico y lo que puede ser terapéutico para cualquier paciente particular está determinado por las capacidades específicas de esa díada particular (u otra constelación terapéutica) y la especificidad de su proceso en despliegue. [...] En cuanto teoría de proceso, la teoría de la especificidad modifica nuestro foco desde una respuesta diseñada como el sine qua non de la cura psicoanalítica hacia el proceso que busca descubrir dentro de cada díada aquello pudiera resultar ser sanador. (p. 15, cursivas del original)

Decisiones clínicas que en un caso pueden resultar ser oportunas y provechosas, en otro caso pueden terminar siendo estériles o incluso afectar de forma negativa, iatrogénica la psicoterapia. Por ejemplo, el mandato psicoanalítico clásico de que un analista nunca puede aceptar el regalo de un paciente, sino que por necesidad debe interpretar el significado del acto de traer un regalo en el psicoanálisis contemporáneo al menos requiere ser matizado. Hoy en día, no es factible equiparar bajo una regla general dos situaciones distintas como una paciente joven y atractiva que todas las sesiones le trae un café a su terapeuta hombre de la misma edad y otra paciente, que puede tener las mismas características físicas y psíquicas, que trae un regalo a su última sesión de un análisis de cinco años que ha tenido muy buenos resultados. La teoría y la técnica psicoanalíticas clásicas tienen ideas bastante claras respecto de cómo proceder con tales situaciones basándose en una norma general -"Nunca se puede aceptar un regalo"-, pero hoy en día la phronesis analítica vuelve indispensable la reflexión y decisión de cómo abordar el comportamiento particular de cada paciente que nos consulta. Así, ni nuestras teorías ni nuestros principios técnicos pueden, en realidad, tomar las decisiones clínicas por nosotros.

En cuanto práctica, ejercer la psicoterapia psicoanalítica implica que toda decisión recae de modo inevitable sobre el psicoterapeuta en cuanto persona. Es el psicoterapeuta quien decide momento a momento si intervenir o no y de qué manera hacerlo. Incluso si escoge actuar de acuerdo a un concepto teórico, a una regla técnica o a lo que le dijo un supervisor o un colega, es siempre e invariablemente él o ella quien decide proceder de ese modo y no de otro en el contexto de una sesión analítica. De acuerdo a Hoffman (1998), esta responsabilidad de tener que elegir sin certidumbre tiende a generar temor y ello puede dar cuenta del apego defensivo a fuentes externas de dirección y decisión tan presente en el psicoanálisis clásico. La circunstancia general descrita por supuesto tiende a traer consigo mayor incertidumbre y al menos a ratos mayor ansiedad. Argumenté en otro lugar que, por lo tanto, la capacidad de regulación afectiva del terapeuta es una dimensión central de la phronesis analítica (Sassenfeld, 2016); tal como afirmó Gadamer (1958) en la 
teoría hermenéutica filosófica, "quien está sobrepasado por sus pasiones ya no ve lo que es recto o no recto" (p. 40), lo cual no significa en ningún caso que el terapeuta no debiera sentir nada o sentirse neutral o desinvolucrado.

Más bien, necesita tanto saber lidiar con los momentos emocionales particulares de especial intensidad que surgen en todo proceso analítico (por ejemplo, la irrupción de afectos de origen traumático) como mantenerse más en general dentro de los límites afectivos trazados por lo que Daniel Siegel (2012 [1999]) llama la ventana de tolerancia (véanse, también, Hill, 2015; Ogden \& Fisher, 2015; y Ogden, Minton \& Pain, 2006) y Beebe y Lachmann (2002) denominan el rango regulatorio óptimo (véase, también, Beebe et al., 2005). Dentro de la ventana de tolerancia es posible integrar los estímulos que provienen del mundo interno y exterior y experimentar una diversidad de afectos en una diversidad de grados de intensidad sin necesidad de disociarlos. La experiencia emocional se mantiene entre los extremos de hiper- e hipoactivación y, con ello, se mantienen amplias las posibilidades de experiencia y reflexión. Dentro de la ventana de tolerancia los afectos propios y ajenos pueden ser mentalizados transformándose en afectividad mentalizada (Fonagy, Gergely, Jurist \& Target, 2002; Jurist, 2018; Wallin, 2007), el resultado óptimo del trabajo analítico.

\section{La phronesis analítica y una psicología de la incertidumbre}

Los teóricos relacionales han buscado amistarse con la experiencia de incertidumbre, que ocupa un lugar central en la experiencia de la phronesis. En palabras de Adrienne Harris (2018 [2011]), el psicoanálisis relacional engloba una comprensión a ratos ansiosa y reticente, a ratos confiada y entusiasta, de que el trabajo analítico transcurre con un irreductible grado de incertidumbre. Para Bacal y Carlton (2011), la técnica psicoanalítica es reemplazada por una capacidad aumentada para tolerar la ansiedad de no conocer de antemano la respuesta que podrá surgir como terapéuticamente útil en el trabajo con un paciente dado. Opino que la noción de phronesis involucra entre otras cosas aprender a tolerar ese frecuente sentimiento en el quehacer diario de un terapeuta relacional. Afirmar la experiencia de incertidumbre con frecuencia posibilita el cambio analítico (Seligman, 2018).

Para Doris Brothers (2008), "una psicología de la incertidumbre es un inevitable acompañamiento de la revolución relacional en el psicoanálisis [...]" (p. ix), mientras que las tendencias cientificistas y objetivistas de Freud lo ubican en mayor cercanía a una psicología de la certidumbre -que guarda relación con sus tendencias cartesianas en cuanto Descartes buscó certeza². En este sentido, Stephen Mitchell (1993) relata cómo muchos 
analistas clásicos "han estado tradicionalmente confiados, incluso han sido a veces autocomplacientes, respecto de la verdad de sus propias convicciones teóricas [...]" (p. 41) a pesar de la intrincada "verdad" inherente a "algo tan complejo y elástico como una teoría psicoanalítica" (p. 50). Subraya que la literatura psicoanalítica tradicional ha tendido a estar escrita con un tono seguro y confiado en relación con sus propias verdades. Mitchell cita a Charles Brenner (1987), un conocido teórico freudiano norteamericano, quien hace solo algunas décadas afirmó que "obviamente" era el analista la persona más capacitada para comprender de modo "correcto" los conflictos de su paciente.

Por lo tanto, siguiendo a Mitchell (1993), los escritos psicoanalíticos tradicionales están llenos de afirmaciones presentadas como verdades que cualquiera con una mente abierta y desprejuiciada tendría que ser capaz de percibir y reconocer. "Las convicciones acumuladas a partir de la práctica analítica cotidiana adoptan una obviedad en la mente del practicante y autor psicoanalítico" (p. 41), obviedad que termina siendo implícita y, con ello, difícil de cuestionar. A ello se suma, según Mitchell, que las verdades psicoanalíticas clásicas tienden a ser "verdades" poco placenteras e incluso desagradables. Por lo tanto, el tono de los escritos analíticos clásicos con frecuencia refleja un cierto orgullo vinculado con la capacidad de tolerar tales verdades perturbadoras. Mitchell considera que la convicción de que el mundo se corresponde con la comprensión psicoanalítica era la dimensión central de la esperanza que los psicoanalistas clásicos podían derivar de su profesión y sistema teórico de creencias. En su opinión, quienes pertenecen al movimiento relacional han experimentado una crisis de la confianza en su propia capacidad de saber; los psicoterapeutas ya no estamos muy seguros de nada y Mitchell enfatiza que adoptar esa postura también requiere coraje.

Desde el punto de vista de Brothers (2008), la incertidumbre puede entenderse como fenómeno relacional en la medida en la que, puesto que no podemos nunca conocer del todo a los demás o a nosotros mismos, lo incierto siempre será una dimensión intrínseca a la experiencia humana. Debido a ello, Brothers subraya que la incertidumbre al igual que todo otro afecto emerge y se transforma en determinados sistemas relacionales. Es decir, la experiencia que un psicoterapeuta dado tenga de la incertidumbre remite a sus experiencias en los sistemas intersubjetivos pasados y presentes en los cuales ha aprendido a regular sus estados emocionales. En términos del desarrollo psíquico, Brothers señala que en el caso óptimo un sistema relacional genera certidumbres emergentes -esto es, predictibilidad y orden- que no son rígidas pero que ayudan al niño a experimentar un mundo que no sea caótico e impredecible. En el desarrollo sano, el apego seguro provee una base para poder con posterioridad lidiar con la realidad de la incertidumbre (Leffert, 2016) y en el mejor de los casos los procesos descritos por Brothers son tan efectivos, que 
el individuo puede vivir "como si la perduración de nuestras vidas psicológicas estuviera asegurada" (Brothers, 2008, p. x). En otras palabras, tal como señala Philip Bromberg (2006), la necesidad de preservar la seguridad emocional organiza la responsividad psíquica frente a la novedad.

Esta idea tiene una relación cercana con lo que Stolorow (2007) en su discusión de la experiencia traumática llama absolutismos de la vida cotidiana -"Nos vemos mañana", "Hasta la próxima semana"-, que son la base de un realismo ingenuo y de un optimismo basal "que le permiten a uno funcionar en el mundo, experimentado como estable y predecible" (p. 16). Tanto para Brothers como para Stolorow, la experiencia traumática aniquila tales aparentes certidumbres $y$, con ello, "expone a sus víctimas a experiencias de intolerable incertidumbre" (Brothers, 2008, p. x) que destruyen las posibilidades de esperanza porque esta precisa tolerancia a la incertidumbre. En consecuencia, la capacidad de tolerar la vivencia de incertidumbre por parte del terapeuta -tal como aseveré recién, un aspecto central de su phronesis analítica- implica por lo general una profunda elaboración terapéutica personal de la propia historia vincular y emocional. Solo habiendo experimentado lo que Brothers describe como certidumbres emergentes en los primeros años de vida y/o en la relación analítica es posible experimentar incertidumbre sin que sea intolerable y por ende traumática.

Stern (1997) hace más de veinte años nos recordó que a su parecer la incertidumbre y la dificultad de sostenerla se han encontrado siempre en el centro del psicoanálisis desde Freud en adelante 3 . En efecto, le parece que la incertidumbre puede ser considerada uno de los valores fundamentales que guían al psicoanálisis y añade:

De hecho, se ha señalado que el monto de incertidumbre que los psicoanalistas tienen que crear y tolerar es directamente proporcional a la proliferación de teorías psicoanalíticas: mientras más ideas tenemos, más incertidumbre tenemos que crear si se pretende que evitemos tratar las teorías como si fueran cuestiones de fe. (p. 61)

Enfatiza que las interpretaciones que pacientes y terapeutas formulan respecto de la experiencia vivida tienden a menudo a traicionar el esfuerzo analítico por mantenerse abierto a la incertidumbre al anular lo incierto y generar una sensación de familiaridad y conocimiento.

Frente a ese trasfondo, Hoffman (1998) destaca que en la situación terapéutica existe una relación dialéctica entre convicción e incertidumbre. Para él, la constatación de la centralidad de la vivencia de incertidumbre entre los teóricos relacionales no desmerece que en múltiples ocasiones tanto paciente como terapeuta pueden experimentar convicción respecto de una determinada interpretación de las cosas con independencia de 
que la implicación de la subjetividad del analista siempre introduce un elemento de incertidumbre en la situación psicoterapéutica. Así, sostener la dialéctica entre convicción y certidumbre es otro aspecto más de la phronesis analítica. Se trata de un aspecto importante ya que, hasta aquí, pudiera parecer que la phronesis analítica solo atañe a lo incierto y su manejo; en realidad, la experiencia phronética con frecuencia toca la posibilidad de sostener certidumbre, por mucho que esta sea momentánea.

El punto de vista de Hoffman es congruente con la hermenéutica filosófica de Gadamer en cuanto esta ha dejado al descubierto que un alejamiento respecto de la verdad entendida en términos de las ciencias naturales como comprobabilidad y certeza en nada invalida la existencia de la experiencia humana de la verdad (Gadamer, 1957). Tal experiencia puede cambiar con rapidez, pero, cuando se produce, un individuo pasa por lo que podríamos visualizar como un momento de verdad, concebido como característica emergente del diálogo (Jaenicke, 2006). Desde ese punto de vista, el psicoanálisis sigue en necesidad de "una concepción pragmática, que da cuenta del falibilismo, de una búsqueda suficientemente buena de la verdad" (Orange, 1995, p. 47). Slochower (2014 [2006]) por su parte asevera que abrazar la incertidumbre nos dificulta alejarnos de las dudas teóricas y clínicas, llevándonos a cuestionar más que a meramente sostener sin mayor reflexión nuestras ideas y creencias. En ese sentido, la incertidumbre cumple una función fundamental para los psicoterapeutas y su mente clínica.

También podríamos afirmar que la vivencia de incertidumbre, cuando se ubica dentro de la ventana de tolerancia antes mencionada, hace indispensable pensar respecto de la situación en la que nos encontramos -en el contexto de que a menudo tenemos que tomar decisiones y actuar mientras la incertidumbre aún persiste (Leffert, 2016). En plena congruencia con el concepto de phronesis, Slochower (2014 [2006]) señala que la tolerancia de la incertidumbre hace menos probable que los psicoterapeutas se vuelvan "rígidos o cerrados de mente en términos clínicos o teóricos" (p. 34). De hecho, para ella implica reubicar lo que percibimos como verdadero en un momento terapéutico específico "en un ámbito transicional entre paciente y terapeuta y, al hacerlo, invitamos al auto-examen y la reflexividad" (p. 34). La idea de reubicar la emergencia de aquello que es experimentado como verdadero en un "ámbito transicional" resuena de forma profunda con la hermenéutica filosófica porque esta afirma que el lugar de emergencia de comprensión transformadora es la conversación genuina entre dos interlocutores.

El hecho de que la toma de decisiones clínicas recaiga sobre el psicoterapeuta en cuanto persona no solo tiende a generar ansiedad e incertidumbre, sino también por otro lado mayor libertad relacional (Stern, 2015) a la hora de buscar formas de estar afectiva y 
relacionalmente con un paciente que resulten ser transformadoras -lo que no quita que tal libertad también puede generar ansiedad tal como señalan Martin Heidegger (1927) y Sartre (1948) así como Erich Fromm (1941) en la filosofía y el psicoanálisis respectivamente. En el psicoanálisis relacional, están aceptados y se entienden como necesarios diversos modos de participación analítica (Hirsch, 2015; Mitchell, 1997; Sassenfeld, 2012a). Según Donnel Stern (2015), su noción de libertad relacional alude al estado de la relación analítica

en el cual el campo [relacional] tiene el mayor grado de libertad para asumir las formas y los contenidos hacia los cuales tiende -esto es, cuando sus propiedades emergentes tienen el mayor grado de libertad para darle forma sin las constricciones introducidas por la intervención defensiva inconsciente por parte del paciente o el analista. (p. 31)

Para numerosos teóricos relacionales, la libertad descrita se puede expresar con cierta frecuencia en intervenciones clínicas marcadas por mayor autenticidad y espontaneidad que las intervenciones basadas en la técnica analítica tradicional (por ejemplo, BCPSG, 2010; Hoffman, 1998; y Sassenfeld, 2012a, 2016). Para Hoffman (1998), en efecto, el psicoanálisis clínico está inserto en una dialéctica continua e irreductible entre ritual analítico y espontaneidad. El desafío permanente de escoger en todo momento clínico respecto nuestro tipo de participación particular en la relación con el paciente es aún otra dimensión fundamental de la phronesis analítica, que trae consigo sostener la dialéctica entre ritual y espontaneidad en el marco de la situación psicoanalítica.

Irwin Hirsch (2008) aclara lo que libertad relacional descrita por Stern ha implicado en términos concretos para los psicoterapeutas (véase, también, Sassenfeld, 2012a, 2016):

Específicamente, hoy existe gran variación en el uso del diván versus un arreglo físico cara-a-cara y, aún más importante, los analistas disponen de un rol más amplio respecto de la cantidad y cualidad de participación verbal. Mientras que a los analistas de otra época se les sugería restringir su participación verbal a preguntas e interpretaciones, es probable que los analistas contemporáneos hagan observaciones subjetivas sobre los pacientes, revelen algo de sus vidas personales y expresen sus hasta ahora estados emocionales privados [...] (p. 47)

En otras palabras, el espectro de posibles intervenciones clínicas aceptables en el psicoanálisis se ha diversificado muchísimo, incluyendo la auto-revelación en determinadas circunstancias. Hace algunos años, intenté subrayar este punto haciendo alusión a las posibilidades de la variedad relacional de la implicación del terapeuta en la relación analítica (Sassenfeld, 2012a), que abarca por ejemplo lo que Philip Ringstrom (2007, 2012) llama improvisación analítica (véase, también, Knoblauch, 2000).

Como queda en evidencia, el psicoterapeuta relacional goza de libertades terapéuticas que en la práctica clínica del psicoanálisis clásico con su concepción más bien 
técnica son impensables; no obstante, lo dicho hasta acá a la vez enfatiza la mayor responsabilidad que trae consigo una aproximación psicoterapéutica que no se apoya en primer lugar en consideraciones técnicas. En efecto, lo que hemos estado describiendo con anterioridad significa que el efecto terapéutico de una psicoterapia es "determinado por las limitaciones y capacidades de cada analista y analizado particular a la hora de comprender y responder uno frente al otro en cualquier momento del tiempo a lo largo del curso de un análisis" (Bacal \& Carlton, 2011, p. 27). Así, la efectividad de una psicoterapia debe visualizarse como función de la especificidad del encaje de quienes participan de una relación analítica particular. Ello muestra que la noción de la phronesis analítica es un concepto que pertenece de manera idónea a un marco psicoterapéutico relacional.

Ahora bien, Mitchell (1997) llamó al aspecto de la phronesis terapéutica vinculado con la toma de decisiones clínicas el compás analítico y escribió:

Creo que todo clínico analítico dispone de una especie de compás para decisiones ligadas a la técnica de tratamiento y de una conciencia que regula el manejo de puntos clínicos de decisión como el descrito y que funciona de modo similar al oráculo de Sócrates. Este expresa en su Apología que tiene una voz interior que nunca le dice lo que debiera hacer, sino que solo le advierte cuando está a punto de cometer un terrible error [...] (p. 217, cursiva del original)

Es decir, el analista dispone de múltiples posibilidades constructivas de intervenir -la voz interior no dice lo que hay que hacer- $y$, por otro lado, su compás analítico está sintonizado con la evitación de errores o fallas significativas. Más allá, Mitchell subrayó que en el compás analítico confluyen múltiples variables incluyendo las experiencias analíticas personales del terapeuta, sus experiencias de supervisión, su formación teórica, su experiencia clínica previa y también sus experiencias de vida (para este último punto, véanse además Klayman Farber, 2017 y Kuchuck, 2014). Glenn Gabbard y Thomas Ogden (2009) describen el proceso de convertirse en psicoanalista justamente como la cristalización de un estilo analítico individual que es resultado del procesamiento crítico y la asimilación integrativa gradual de todas las variables enumeradas. En la psicología analítica jungiana, este proceso es llamado la individuación del analista y hace referencia, tal como afirma Jung en una de sus habituales formulaciones paradójicas, al proceso de convertirse en lo que uno es (véase Sassenfeld, 2012b).

Por supuesto, lo dicho coloca mayor responsabilidad sobre el psicoterapeuta que una aproximación terapéutica basada en la teoría o en la aplicación de técnicas, donde al menos para muchas situaciones clínicas parecen existir decisiones formuladas de antemano. En las aproximaciones centradas en la teoría y/o en la técnica tienden a carecer de relevancia, al menos en gran medida, las inevitables variables contextuales. La mayor 
responsabilidad propia de un enfoque como aquel que estamos describiendo en este trabajo podría convertirse en un gran peso para los terapeutas y, en cierto sentido, es así: no existe teoría o técnica que nos dicte sin lugar a dudas lo que es indicado decir o hacer. No obstante, la elaboración de la noción griega de la phronesis en la filosofía hermenéutica de Gadamer trae consigo el descarte de la categoría dicotómica correcto/incorrecto a la hora de evaluar nuestras decisiones. En palabras de Maroda (1998), no puede asumirse que "lo correcto es, en última instancia, el factor determinante en términos de si la interpretación es o no terapéutica" (p. 169).

La phronesis analítica genera respuestas tentativas que intentan encajar con lo que la situación presente parece requerir, escogiéndolas de entre las simultáneas posibilidades y limitaciones existentes, y abarca la posibilidad de implicarse en un proceso de ir modificando nuestras intervenciones en función de lo que van generando en la interacción con un paciente dado (insisto, siempre y cuando las intervenciones se encuentren dentro de los márgenes de lo razonable 4 desde el punto de vista clínico). Seguirle la pista a lo que nuestra intervención provoca en la situación analítica termina siendo un principio fundamental del trabajo analítico de orientación relacional (Lichtenberg, 2005; Lichtenberg, Lachmann \& Fosshage, 1992, 1996; Maroda, 2010; Sassenfeld, 2012a, 2016). Así, "es más una pregunta de lo que el paciente es capaz de escuchar, comprender y usar en cualquier momento dado" (Maroda, 1998, p. 169) que de imponer nuestras ideas teóricas y/o técnicas.

De este modo, la relativización radical de la dicotomía de lo correcto/incorrecto ayuda a desculpabilizar los "errores" que puede cometer el psicoterapeuta dentro del marco de lo razonable práctica, clínica y éticamente con tal de convertirlos más bien en objeto de comprensión analítica. El trabajo de Ferenczi, Kohut y quienes han subrayado la noción relacional del enactment nos muestra que la repetida falla del psicoterapeuta es una parte inevitable de todo proceso analítico. Según Mitchell (2000), una de las propiedades más potentes de la literatura psicoanalítica relacional es que a ratos adopta un tono de liberación dramática respecto de los dogmas técnicos tradicionales basados en la dicotomía correcto/incorrecto que contrasta con el tono de reserva que ha predominado en la teoría y práctica asépticas del psicoanálisis clásico. Para Mitchell, muchos de los escritos relacionales de las décadas de 1980 y 1990 comunican en especial un espíritu de liberación por parte del psicoterapeuta vinculado con la posibilidad de y libertad para implicarse emocionalmente con los pacientes. Ese espíritu de liberación permite la expresión de la subjetividad del analista y convierte las complejidades de su experiencia subjetiva en parte constituyente del proceso analítico. 
Ahora bien, aunque Mitchell (2000) expresa cierta preocupación respecto de la posibilidad de un exceso de expresión de la subjetividad del terapeuta (véase, también, Slochower, 2018), considero que hasta el día de hoy la literatura psicoanalítica relacional ha tendido a descripciones expresivas de la experiencia subjetiva presente del analista, pero peca de estrechez respecto de la historia personal de los psicoterapeutas y las múltiples formas en las que esta se manifiesta en la vivencia que los terapeutas tenemos en la la relación analítica. Parece persistir un cierto pudor a la hora de revelar aspectos importantes de la propia historia emocional y vincular -que, por supuesto, guarda relación con una sensación de exposición personal y, por ende, de estar expuesto a los juicios de otros. Aún así, existen algunas significativas excepciones en el trabajo de teóricos analíticos como Chris Jaenicke (2006, 2011, 2014), Lichtenberg (2016), Orange (2010), William Cornell (2019) o los teóricos que participaron en el tomo editado por Kuchuck (2014) (véase, además, Hunter, 1994), pero a pesar de ello en mi opinión la reserva respecto de la propia historia emocional por lo común sigue predominando. Con frecuencia, se revelan sentimientos que surgen en la experiencia presente del terapeuta respecto de un cierto paciente, pero a mi parecer no es habitual encontrar en la literatura relacional revelaciones explícitas en relación con su historia afectiva o con la historia relacional que subyace a tales experiencias.

En este sentido, no estoy del todo de acuerdo con Mitchell (2000) respecto de que para muchos teóricos analíticos la auto-revelación se puede haber convertido en una virtud y meta de los escritos analíticos, aunque ciertamente es una dimensión de buena parte de la literatura relacional. Como sea, siguiendo a Mitchell esa tendencia de algunos teóricos relacionales dio pie a la crítica de muchos teóricos más clásicos respecto de que por lo tanto en el psicoanálisis relacional "todo vale". "Los analistas de orientación relacional no pocas veces son retratados como analistas silvestres que hacen y dicen todo lo que se les ocurre sin inhibiciones" (p. 185), una apreciación que omite el concepto de phronesis que hemos estado examinando en este trabajo. En contraste, Mitchell comenta que siguiendo su propia experiencia los terapeutas relacionales tienden a ser más bien un grupo que trabaja de forma tanto teórica como clínica con un alto grado de reflexión y cuidado. Su opinión vuelve a destacar la dimensión ética de la phronesis.

Por supuesto, el exponencial crecimiento del movimiento psicoanalítico relacional implica que puedan existir terapeutas que se consideran a sí mismos relacionales y que ejercen de acuerdo a una especie de "todo vale"; sin embargo, lo que Mitchell (2000) está intentando aclarar es que el "todo vale" en ningún sentido define la psicoterapia analítica relacional. Afirma respecto de los sentimientos del psicoanalista en relación con sus pacientes: 
Una regla general respecto de ser reservado respecto de estos o de si expresarlos no tiene sentido como línea directriz para el manejo que el analista tenga de sus propios sentimientos. Ambas cosas, reserva y espontaneidad, pueden ser planificadas o irreflexivas. Forma parte del núcleo del arte psicoanalítico lidiar con tales dimensiones emocionales, hacer con ellas lo que en un momento dado parezca la mejor decisión y cuestionar decisiones anteriores una y otra vez con la finalidad de ampliar y enriquecer el contexto dentro del cual las decisiones actuales son tomadas. (p. 209)

Una vez más, la phronesis analítica es visualizada como capacidad contextual que lidia con las profundas complejidades de la experiencia humana en torno a la subjetividad y la intersubjetividad.

Con todo, Maroda (1998) argumentó de manera similar que, al margen de la tolerancia que el psicoanálisis relacional plantea en términos generales frente a una diversidad de formas particulares de ejercer la práctica analítica, sin duda siguen existiendo modos "correctos" e "incorrectos" específicos de tratar con nuestros pacientes. Insiste en que la experiencia clínica y supervisatoria la ha convencido de que ciertas actitudes y comportamientos por parte de los psicoterapeutas casi siempre resultan ser destructivos para la relación y el proceso analíticos. Incluye las más evidentes transgresiones a los límites propios del vínculo terapéutico, pero también menciona la "defensividad, la no responsividad, el rechazo a estar disponible para un paciente que pregunta respecto de nuestras percepciones, etc." (p. 8) -esto es, ciertas actitudes y comportamientos en la vinculación con los pacientes que son congruentes con cómo los teóricos relacionales entienden la postura psicoterapéutica necesaria del analista (véase, por ejemplo, Sassenfeld, 2010, 2012a, 2016, 2017, 2018, 2019).

Así, "mientras que todos tenemos que encontrar nuestro propio camino y voz, no creo que todo sea relativo o único a una determinada díada terapéutica" (Maroda, 1998, p. 8) ya que existen en toda comunidad terapéutica algunas ideas importantes y consensuadas -además de que contamos con determinadas regulaciones legales en gran parte de los países en los cuales se ejerce la psicoterapia- respecto de las actitudes aceptables y necesarias por parte de los psicoterapeutas. Maroda subraya que la individualidad de todo analista solo puede emerger constructivamente en el marco de una estructura y aproximación clínicas básicas y a la vez de la responsabilidad de los terapeutas respecto de sus pacientes. Algunos aspectos sombríos y disociados respecto de esta postura básica son descritos de modo interesante por Joyce Slochower (2013) como los delitos secretos del analista. 


\section{Reflexiones finales}

Tal como espero haber podido ir mostrando en este trabajo, la práctica del psicoanálisis relacional requiere por parte del psicoterapeuta aún mayor reflexividad y disciplina que cualquier aproximación terapéutica basada en la noción de teoría y/o de técnica. La mente analítica phronética implica más -y no menos- que la mente analítica tradicional en cuanto no se puede estandarizar. Por ejemplo, Hoffman (1998) subrayó que la ocasional espontaneidad de un terapeuta solo adquiere sentido y puede manifestar un importante impacto en la relación analítica y en el paciente frente al trasfondo de la ritualidad que toda díada terapéutica desarrolla en su labor conjunta. Un momento espontáneo interrumpe la rutina terapéutica y justo debido a ello puede adoptar significados que no tendría de otro modo y en otros contextos (véanse, también, BCPSG, 2010; Stern, 2004; y Stern et al., 1998). La phronesis analítica implica una continua reflexión disciplinada respecto de la experiencia subjetiva e intersubjetiva $y$, debido a ello, da cuenta de una mente clínica más compleja que la mente psicoanalítica tradicional.

Lichtenberg, Lachmann y Fosshage (1996) conceptualizaron la existencia de involucramientos espontáneos disciplinados entre paciente y terapeuta, una idea que busca capturar la inextricabilidad paradójica de los aspectos auténticos y espontáneos del analista con su simultánea consciencia y responsabilidad respecto de que está realizando un trabajo profesional -una espontaneidad disciplinada o una autenticidad reflexiva. Más allá, me parece que la amplia difusión e influencia del concepto de mentalización en las últimas décadas entre otras cosas se relaciona con que proporciona una descripción del estado y la actividad psíquica reflexiva ligada a los afectos que es necesario para ejercer la psicoterapia de manera exitosa en cualquier enfoque terapéutico (Allen, Fonagy \& Bateman, 2008; DeYoung, 2015 [2003]; Fonagy, Gergely, Jurist \& Target, 2002; Hill, 2015; Jurist, 2018; Sassenfeld, 2012a; Wallin, 2007). Facilitar la mentalización del paciente respecto de su propia experiencia precisa y presupone la presencia de un grado razonable de esa capacidad en el psicoterapeuta.

Ahora bien, respecto de la culpa del psicoterapeuta y su posibilidad de cometer errores, hemos pasado a hacer uso de criterios para evaluar nuestras intervenciones y su pertinencia y utilidad que son más pragmáticos -aquello que facilita u obstaculiza el proceso terapéutico (Bacal \& Carlton, 2011; Renik, 2006; Safran 2012)- o vivenciales aquello que vitaliza o desvitaliza el proceso terapéutico (Lichtenberg, Lachmann \& Fosshage, 2016; Mitchell, 1997; Ogden, 1995). Tal como señala Theodore Jacobs (2013), nos importa que nuestros pacientes puedan hacer uso de la comprensión analítica al servicio de realizar cambios personalmente significativos en sus vidas. 
El psicoanálisis relacional, en el mejor de los sentidos, desculpabiliza el error terapéutico sin volverlo irrelevante -todo lo contrario. En palabras de Mitchell (1997), muy cercanas a la definición que Stolorow, Brandchaft y Atwood (1987) ofrecen de la meta del psicoanálisis relacional como ampliación de las posibilidades de experiencia subjetiva e intersubjetiva (véase, además, Stolorow, Atwood \& Orange, 2002):

Por lo tanto, uno de mis propósitos más importantes es darle forma a mi participación de tal manera, que a través de esta las posibilidades de experiencia del paciente se vean relativamente poco restringidas y que además le ayude también a disminuir sus propias restricciones existentes. (p. 253)

Se trata, tal como mencionamos, de lo que Stern (2015) llama la libertad para experienciar, que es libertad para hacer uso de nuestras mentes o, con mayor exactitud, "la disposición a permitir a nuestras mentes su libertad" (p. 109) en cuanto cualquier novedad en nuestra propia experiencia debe entenderse como algo que nos acontece más que como algo que logramos o hacemos de modo consciente.

Para Stern (2015), la libertad para experienciar es sinónimo del proceso de articular o formular explícitamente la experiencia no formulada, su concepción de lo inconsciente (véanse Eagle, 2011; Sassenfeld, 2012a; y Stern, 1997, 2010, 2019), y en consecuencia equivale a una concepción relacional de lo que significa hacer consciente lo inconsciente. Más allá, siguiendo a Stern, cambios en el campo interpersonal entre paciente y analista constituyen cambios en las formas de vinculación entre ambos que pueden emerger. Desde ese punto de vista, "la libertad para experienciar -esto es, nuestro acceso al rango más amplio de experiencia espontánea- descansa sobre lo que podríamos denominar libertad relacional [...]" (p. 113, cursiva del original), concepto que ya mencionamos. Así, advertir que la propia forma de participar en la interacción con un determinado paciente no contribuye a facilitar sus posibilidades de experiencia no es sinónimo de una equivocación por parte del psicoterapeuta, sino de que es momento de revisar qué otras formas de participación pudieran ser más útiles en esa situación particular. En palabras de Stern, lo que sea que podamos hacer para que la relación terapéutica se desarrolle con un mínimo de restricciones, constricciones e inhibiciones resultará ser la mejor manera de facilitar la libertad para experienciar. "La libertad relacional vuelve posible la libertad para experienciary, por lo tanto, apuntala la acción terapéutica" (p. 114).

Todo lo discutido en este trabajo no implica perder de vista que los analistas al margen de su phronesis analítica más o menos desarrollada -o, tal vez, más bien en el seno de esta- a menudo experimentan dificultades para percibir con claridad sus propias motivaciones y sentimientos. Tal como expresa Maroda (1998), en parte todos los terapeutas experimentamos de manera consciente y/o inconsciente el deseo de ser 
percibidos como inocentes y cuidadosos en nuestro actuar clínico, como aquello que los teóricos de las relaciones objetales han llamado un objeto nuevo bueno. Si nos equivocamos, por lo común asumiremos que fue un error honesto cuya motivación más profunda son las buenas intenciones hacia el paciente. Fue resultado de la "ignorancia o la ingenuidad más que de las malas intenciones. Asumir la responsabilidad sobre nuestra rabia, odio, sadismo, envidia, de nuestro deseo de destruir tanto lo que amamos como lo que odiamos no es fácil" (p. 23). De acuerdo a Maroda, los psicoterapeutas analíticos hemos cargado históricamente con el peso de ser concebidos como quienes son capaces de generar un acceso a la verdad respecto de uno mismo -por mucho que hoy en día, en el marco de los giros fenomenológico y hermenéutico del psicoanálisis contemporáneo (Sassenfeld, 2018, 2019), esa "verdad" se ha convertido en la experiencia de la verdad respecto de la propia experiencia y su comprensión terapéutica interpretativa. Muchas veces "no admitimos cuán sobrecogedoramente difícil esta tarea es y cuánto estamos destinados a fallar" (Maroda, 1998, p. 23).

Recientemente, desde una perspectiva que se puede entender como postura crítica o bien ambivalente respecto del concepto de phronesis (aunque de modo llamativo ni siquiera hace alusión a este), Steven Tublin (2018) ha hecho referencia a que el movimiento relacional generó una significativa y necesitada libertad a la hora de ejercer la práctica analítica, pero que a la vez precisa a menudo de crítica respecto de las limitaciones impuestas por la técnica psicoanalítica tradicional sin articular de forma clara lo que un terapeuta relacional debiera efectivamente hacer con su libertad clínica -frente al imperativo de no codificar algún tipo de versión de una técnica relacional (véase, también, Rodríguez Sutil, 2012). Desde su punto de vista, "existe un conflicto inherente al psicoanálisis relacional entre la libertad requerida para responder a momentos clínicos envueltos en términos contextuales y la disciplina requerida para llevar a cabo un tratamiento psicoanalítico coherente con propósito" (p. 69). Más allá, considera que el pluralismo característico del psicoanálisis relacional "ha creado una situación en la cual el analista enfrenta un amplio espectro de elecciones técnicas que puede ser excitante en su plenitud o inductor de pánico en su ausencia de límites" (p. 69). Por supuesto, el concepto de una phronesis analítica justamente da cuenta de tal situación y de la posible forma de enfrentarla.

A Tublin (2018) parece preocuparle que la libertad analítica pudiera hacer al psicoterapeuta perder de vista las metas terapéuticas que encauzan su libertad o lo que Tublin llama su propósito o intención terapéutica o también su teoría de la acción terapéutica (por ejemplo, elaborar conflictos psíquicos, articular experiencia no formulada o generar una experiencia relacional novedosa). Me parece que la preocupación de Tublin 
es legítima, sobre todo respecto de la formación psicoanalítica, pero que desconoce por un lado que la noción de la phronesis analítica justamente busca describir lo que un analista debiera hacer con su libertad clínica. Por otro lado, pasa por alto que muchos teóricos relacionales relevantes han hecho esfuerzos por explicitar sus ideas respecto de las metas del proceso terapéutico y las "libertades" clínicas que pudieran estar implicadas en seguir tales metas. En otras palabras, el planteamiento de Tublin parece sobre-enfatizar potenciales riesgos clínicos y pasar por alto en alguna medida las posibilidades terapéuticas que la aproximación relacional trae consigo.

Para ir concluyendo esta discusión de la centralidad de la phronesis analítica es importante hacer alusión a la relación entre phronesis, consciencia y reflexión. En el contexto del psicoanálisis, como todo fenómeno la phronesis tiene que abarcar dimensiones tanto conscientes como no conscientes e inconscientes. En efecto, cuando se habla de intuición analítica, por lo común se hace referencia a un complejo proceso subjetivo de procesamiento del cual en general sólo el resultado final encuentra acceso a la consciencia del terapeuta. Así, la toma phronética de decisiones clínicas -que está fundamentada en procesos implícitos no conscientes y/o en procesos explícitos más conscientes de inferencia acerca de lo que el psicoterapeuta percibe y siente (Lichtenberg, Lachmann \& Fosshage, 2011; Slochower, 2014 [2006])- puede darse vivencialmente de forma intuitiva e implícita o de forma reflexiva y explícita.

Algunas situaciones son resueltas con relativa fluidez y facilidad gracias a nuestro conocimiento clínico implícito (Sassenfeld, 2016) que es resultado de nuestra experiencia clínica previa, una parte fundamental de la subjetividad del analista en cuanto sujeto hermenéutico -esto es, en cuanto animal hermenéutico que busca comprender e interpretar su mundo (Angehrn, 2010; Greisch, 1993; Sassenfeld, 2016; Taylor, 1985). Otras situaciones requieren una reflexión más consciente para lidiar con ellas, a menudo debido a que su complejidad implica evaluar varias vías de acción diferentes. Desde ese punto de vista, un componente principal de la reflexión phronética consciente es a mi parecer la capacidad de pensamiento crítico. Fromm (1974) llegó a afirmar que el psicoanálisis es, en efecto, "un método para pensar críticamente" (p. 117) y consideró indispensable no sólo que un analista fuera capaz de pensamiento crítico en términos clínicos, sino también en términos sociales y culturales. Para él, una parte constituyente de la tarea analítica es ayudar al paciente a pensar críticamente respecto de sí mismo, los demás y, en especial, la cultura a la cual pertenece y el lugar que ocupa en esta.

En ambos casos, se dé la phronesis de modo tácito o reflexivo, el manejo implícito y/o explícito de teorías analíticas particulares es esencial, inevitable y necesario en los 
procesos de inferencia que culminan en nuestras decisiones clínicas. En efecto, es un aspecto esencial de nuestra pertenencia a una tradición teórica y práctica del psicoanálisis (Mitchell \& Aron, 1999). En palabras de Slochower (2014 [2006]), nunca dejamos de usar o necesitar nuestras teorías; solo que estas con el paso del tiempo pasan a formar parte "de nosotros dejando de ser un bastón en el cual nos apoyamos cuando sentimos que no tenemos recursos" (pp. 42-43) y, más allá, aunque sea de modo implícito tampoco dejan de transformarse frente al impacto de nuevas experiencias clínicas y personales y de la exposición a las ideas de otros teóricos analíticos. Nuestras teorías, tanto aquellas que preferimos como aquellas que tendemos a rechazar, son una dimensión básica de lo que Gadamer (1960) en un sentido no peyorativo llamó nuestro prejuicio y que yo llamé el sujeto hermenéutico (Sassenfeld, 2016) -esto es, nuestra irreductible subjetividad que, al mismo tiempo, posibilita y limita nuestra comprensión.

Es más, tal como asevera Emmanuel Ghent (1989), nuestras teorías analíticas deben ser visualizadas como sistemas de creencias con un gran impacto en "cómo uno escucha, lo que uno escucha, cómo uno ensambla lo escuchado y cómo uno se comporta en el setting analítico" (p. 29). Lo que creemos nos hace percibir las cosas de determinado modo y, con ello, nos inclina a actuar de cierta forma. Ghent pensaba que honramos a nuestras creencias llamándolas teorías. Ya Heinz Kohut $(1977,1984)$ hizo hincapié en que las teorías que un psicoanalista conoce y ha integrado en su manera de ejercer determinan directamente el alcance en términos de posibilidades y limitaciones de su capacidad de empatía y comprensión del paciente (véanse también Wolf, 1988 y Ornstein, 1995). Es en este sentido que entiendo la propuesta de Mitchell de concebir el pensamiento relacional como un psicoanálisis comparativo (Ringstrom, 2010): mientras más teorías analíticas conozco, más amplias y ricas son mis posibilidades de comprensión. Por otro lado, la "comparación" o quizás, mejor dicho, contrastación de las contribuciones de diferentes teóricos psicoanalíticos a menudo promueve el pensamiento crítico que tan central resulta ser en la phronesis analítica.

Entonces, frente al trasfondo de toda la discusión ya realizada en este trabajo, ¿existe finalmente una técnica psicoanalítica relacional? Carlos Rodríguez (2012) argumenta a favor de la posibilidad de generar ciertas formulaciones teórico-clínicas que podemos llamar técnicas. No obstante, su opinión parece ser minoritaria entre los teóricos relacionales, por mucho que tal perspectiva trae consigo desafíos y dificultades importantes en términos de la formación psicoanalítica. Ello queda en evidencia en la discusión de este trabajo y, más allá, se expresa con cierta ironía en las siguientes palabras de Bromberg (1998): la 
técnica analítica adecuada yace en la habilidad del analista para tener cuidado de su presencia, para estar tan entonado como sea posible con aquellos momentos en los que la aplicación de la "técnica" ha reemplazado una postura organizado en torno al involucramiento en curso con la experiencia del paciente. [...] cualquier postura analítica sistematizada contiene el potencial de repetir el trauma de la falta de reconocimiento, con independencia de lo útil que pueda ser la teoría de la cual deriva la postura. La falta de reconocimiento equivale a un abandono relacional [...] (p. 258, cursiva del original)

No resulta demasiado dificultoso percibir ecos ferenczianos en estas ideas. Asimismo, vuelve a quedar a modo de conclusión al descubierto que el contacto del terapeuta con la experiencia vivida del paciente, así como el contacto intersubjetivo entre paciente y analista predomina clínicamente a la hora de tomar decisiones prácticas por sobre cualquier idea técnica acerca de cómo se supone que es correcto proceder en una determinada situación.

Para cerrar este trabajo, me gustaría aún hacer referencia a una interesante idea de Steven Stern (2017) respecto de la subjetividad del psicoanalista. Stern destaca que el equivalente terapéutico de una madre o un padre suficientemente buenos implica sin excepción un alto grado de "complejidad en la subjetividad-como-analista del analista (consciente, implícita, inconsciente) y en las capacidades observacionales, de procesamiento, intuitivas, interpretativas y relacionales que derivan de y expresan esa complejidad subjetiva" (pp. 28-29, cursiva del original). Creo que esta idea resume con claridad lo que hemos estado llamando en esta sección phronesis analítica. La phronesis analítica es, justamente, tal como hemos visto un fenómeno de gran complejidad -a ello se debe que sea tan dificultoso definirla con precisión en términos conceptuales más allá de que, con seguridad, haber leído este trabajo permite quedarse con una idea quizás intuitiva y experiencial de su naturaleza.

Desde el punto de vista vivencial del psicoterapeuta, todo momento analítico requiere de "un involucramiento con atención plena, donde ciencia y arte se encuentran y es necesario tomar decisiones momento-a-momento, esencialmente creativas que siempre afectan el destino al servicio de facilitar el movimiento del paciente [...]" (Stern, 2017, p. 29). Resulta en realidad impactante la variedad de teóricos relacionales que han intentado describir y dar cuenta del estado psíquico del terapeuta fuera del marco técnico del psicoanálisis clásico en un sentido más fenomenológico que invariablemente conduce al terreno de la complejidad psíquica y relacional. Sin duda, nos queda mucho por aprender respecto de las capacidades y estados psíquicos que inciden en la subjetividad de un psicoterapeuta que hace un buen trabajo. Por ahora, tendremos que conformarnos con la constatación de que la complejidad psicológica es una variable central. 


\section{REFERENCIAS}

Alexander, F. \& French, T. (1946). Psychoanalytic Therapy: Principles and Application. New York: Ronald Press.

Allen, K., Fonagy, P. \& Bateman, A. (2008). Mentalizing in Clinical Practice. Virginia: American Psychiatric Publishing.

Angehrn, E. (2010). Sinn und Nicht-Sinn: Das Verstehen des Menschen. Tübingen: Mohr Siebeck.

Atwood, G. \& Stolorow, R. (1997). Defects in the self: Liberating concept or imprisoning metaphor? Psychoanalytic Dialogues, 7 (4), 517-522.

Bacal, H. (1998). Preface. En H. Bacal (Eds.), Optimal Responsiveness; How Therapists Heal Their Patients (pp. xi-xiv). New Jersey: Jason Aronson.

Bacal, H. \& Carlton, L. (2011). The Power of Specificity in Psychotherapy: When Therapy Works -And When it Doesn't. New Jersey: Jason Aronson.

Bass, A. (2007). When the frame doesn't fit the picture. Psychoanalytic Dialogues, 17, 1-27.

Beebe, B., Knoblauch, S., Rustin, J. \& Sorter, D. (2005). Forms of Intersubjectivity in Infant Research and Adult Treatment. New York: Other Press.

Beebe, B. \& Lachmann, F. (2002). Säuglingsforschung und die Psychotherapie Erwachsener: Wie interaktive Prozesse entstehen und zu Veränderung führen. Stuttgart: Klee-Cotta.

Berman, E. (2004). Impossible Training: A Relational View of Psychoanalytic Education. New York: Routledge.

Bernstein, R. (1983). Beyond Objectivism and Relativism: Science, Hermeneutics, and Praxis. Philadelphia: University of Pennsylvania Press.

Bion, W. (1957). Differentiation of the psychotic from the non-psychotic personalities. International Journal of Psychoanalysis, 38, 266-275.

Boston Change Process Study Group (BCPSG) (2010). Change in Psychotherapy: A Unifying Paradigm. New York: W. W. Norton.

Brenner, C. (1987). A structural theory perspective. Psychoanalytic Inquiry, 7 (2), 167-172.

Bromberg, P. (1998). Standing in the Spaces: Essays on Clinical Process, Trauma, and Dissociation. New York: Psychology Press.

Bromberg, P. (2006). Awakening the Dreamer: Clinical Journeys. New Jersey: The Analytic Press.

Brothers, D. (2008). Toward a Psychology of Uncertainty: Trauma-Centered Psychoanalysis. New York: Routledge.

Buechler, S. (2008). Making a Difference in Patients' Lives: Emotional Experience in the Therapeutic Setting. New York: Routledge.

Cavell, M. (1993). The Psychoanalytic Mind: From Freud to Philosophy. Cambridge: Harvard University Press. 
Cornell, W. (2019). Self-Examination in Psychoanalysis and Psychotherapy: Countertransference and Subjectivity in Clinical Practice. New York: Routledge.

DeYoung, P. (2015 [2003]). Relational Psychotherapy: A Primer (2. Ed.). New York: Routledge.

Drozek, R. (2019). Psychoanalysis as an Ethical Process. New York: Routledge.

Eagle, M. (2011). From Classic to Contemporary Psychoanalysis: A Critique and Integration. New York: Routledge.

Etchegoyen, H. (2002 [1986]). Los fundamentos de la técnica psicoanalítica (2. Ed.). Buenos Aires: Amorrortu.

Ferenczi, S. (1928). The elasticity of psychoanalytic technique. En S. Ferenczi, Final Contributions to the Problems and Methods of Psychoanalysis (pp. 87-101). London: Karnac Books.

Ferenczi, S. (1949 [1933]). Confusion of the tongues between the adults and the child -The language of tenderness and passion. International Journal of Psychoanalysis, 30, 225-230.

Fonagy, P., Gergely, G., Jurist, E. \& Target, M. (2002). Affektregulierung, Mentalisierung und die Entwicklung des Selbst. Stuttgart: Klett-Cotta.

Freud, S. (1910). Über "wilde" Psychoanalyse. En S. Freud, Schriften zur Behandlungstechnik (pp. 133-141). Frankfurt am Main: S. Fischer Verlag.

Freud, S. (1912). Ratschläge für den Arzt bei der psychoanalytischen Behandlung. En S. Freud, Schriften zur Behandlungstechnik (pp. 169-180). Frankfurt am Main: S. Fischer Verlag.

Fromm, E. (1941). Die Furcht vor der Freiheit. München: Deutscher Taschenbuch Verlag.

Fromm, E. (1974). Therapeutische Aspekte der Psychoanalyse. En E. Fromm, Von der Kunst des Zuhörens: Therapeutische Aspekte der Psychoanalyse (pp. 47-226). Alemania: Ullstein.

Gabbard, G. \& Ogden, T. (2009). On becoming a psychoanalyst. En L. Aron \& A. Harris (Eds.), Relational Psychoanalysis: Evolution of Process (Vol. 5) (pp. 407-425). New York: Routledge.

Gadamer, H.-G. (1957). Was ist Wahrheit? En H.-G. Gadamer, Hermeneutik II: Wahrheit und Methode. Ergänzungen und Register (Gesammelte Werke II) (pp. 44-56). Tübingen: J. C. B. Mohr.

Gadamer, H.-G. (1958). Das hermeneutische Problem und die aristotelische Ethik. En H.-G. Gadamer, Das Problem des historischen Bewusstseins (pp. 33-41). Tübingen: Mohr Siebeck.

Gadamer, H.-G. (1960). Wahrheit und Methode: Grundzüge einer philosophischen Hermeneutik (Gesammelte Werke I). Tübingen: Mohr Siebeck.

Ghent, E. (1989). Credo: The dialectics of one-person and two-person psychologies. En V. Demos \& A. Harris (Eds.), The Collected Papers of Emmanuel Ghent: Heart Melts Forward (pp. 28-70). New York: Routledge.

Gill, M. (1994). Psychoanalysis in Transition: A Personal View. New Jersey: The Analytic Press.

Goodman, D. \& Severson, E. (Eds.) (2016a). The Ethical Turn: Otherness and Subjectivity in Contemporary Psychoanalysis. New York: Routledge.

Greisch, J. (1993). Hermeneutik und Metaphysik: Eine Problemgeschichte. München: Wilhelm Fink Verlag. 
Harris, A. (2018 [2011]). The relational tradition: Landscape and canon. En R. Barsness (Ed.), Core Competencies of Relational Psychoanalysis: A Guide to Practice, Study, and Research (pp. 43-64). New York: Routledge.

Heidegger, M. (1927). Sein und Zeit. Tübingen: Max Niemeyer Verlag.

Hill, D. (2015). Affect Regulation Theory: A Clinical Model. New York: W. W. Norton.

Hirsch, I. (2008). Coasting in the Countertransference: Conflicts of Self Interest Between Analyst and Patient. New York: Routledge.

Hirsch, I. (2015). The Interpersonal Tradition: The Origins of Psychoanalytic Subjectivity. New York: Routledge.

Hoffman, I. (1998). Ritual and Spontaneity in the Psychoanalytic Process: A Dialectical-Constructivist View. New York: The Analytic Press.

Horney, K. (1987 [1952]). Final Lectures. New York: W. W. Norton.

Horney, K. (1956). Understanding the patient as the basis of all technique. En K. Horney, The Therapeutic Process: Essays and Lectures (Ed. B. Paris) (pp. 198-205). New Haven: Yale University Press.

Horney, K. (1957). The analyst's personal equation. En K. Horney, The Therapeutic Process: Essays and Lectures (Ed. B. Paris) (pp. 191-197). New Haven: Yale University Press.

Hunter, V. (1994). Psychoanalysts Talk. New York: Guilford Press.

Jacobs, T. (2013). The Possible Profession: The Analytic Process of Change. New York: Routledge.

Jaenicke, C. (2006). The Risk of Relatedness: Intersubjectivity Theory in Clinical Practice. Maryland: Jason Aronson.

Jaenicke, C. (2011). Change in Psychoanalysis: An Analyst's Reflections on the Therapeutic Relationship. New York: Routledge.

Jaenicke, C. (2014). Die Suche nach Bezogenheit: Eine intersubjektiv-systemische Sicht. Frankfurt am Main: Brandes \& Apsel.

Jung, C. G. (1946 [1926]). Analytische Psychologie und Erziehung. En C. G. Jung, Über die Entwicklung der Persönlichkeit (Gesammelte Werke 17) (pp. 77-153). Düsseldorf: Walter Verlag.

Jung, C. G. (1943 [1942]). Psychotherapie und Weltanschauung. En C. G. Jung, Praxis der Psychotherapie (Gesammelte Werke 16) (pp. 86-93). Düsseldorf: Walter Verlag.

Jurist, E. (2018). Minding Emotions: Cultivating Mentalization in Psychotherapy. New York: Guilford Press.

Kernberg, O. (1996). Thirty methods to destroy the creativity of psychoanalytic candidates. International Journal of Psychoanalysis, 77 (5), 1031-1040.

Klayman Farber, S. (Ed.) (2017). Celebrating The Wounded Healer Psychotherapist: Pain, PostTraumatic Growth, and Self-Disclosure. New York: Routledge.

Kohut, H. (1977). The Restoration of the Self. Chicago: Chicago University Press.

Kohut, H. (1984). How Does Analysis Cure? Chicago: Chicago University Press. 
Knoblauch, S. (2000). The Musical Edge of Therapeutic Dialogue. New Jersey: The Analytic Press.

Kuchuck, S. (Ed.) (2014). Clinical Implications of the Psychoanalyst's Life Experience: When the Personal Becomes Professional. New York: Taylor and Francis.

Leffert, M. (2016). Phenomenology, Uncertainty, and Care in the Therapeutic Encounter. New York: Routledge.

Lichtenberg, J. (2005). Kunst und Technik psychoanalytischer Therapien. Frankfurt am Main: Brandes \& Apsel.

Lichtenberg, J. (2016). A Developmentalist's Approach to Research, Theory, and Therapy: The Selected Works of Joseph D. Lichtenberg. New York: Routledge.

Lichtenberg, J., Lachmann, F. \& Fosshage, J. (1992). Selfand Motivational Systems: Toward a Theory of Psychoanalytic Technique. New York: Routledge.

Lichtenberg, J., Lachmann, F. \& Fosshage, J. (1996). The Clinical Exchange: Techniques Derived From Self and Motivational Systems. New York: Routledge.

Lichtenberg, J., Lachmann, F. \& Fosshage, J. (2011). Psychoanalysis and Motivational Systems: A New Look. New York: Routledge.

Lichtenberg, J., Lachmann, F. \& Fosshage, J. (2016). Enlivening the Self: The First Year, Clinical Enrichment, and the Wandering Mind. New York: Routledge.

Loewald, H. (1974). Psychoanalysis as an art and the fantasy character of the analytic situation. En H. Loewald, Papers on Psychoanalysis (pp. 352-371). New Haven: Yale University Press.

Maroda, K. (1998). Seduction, Surrender, and Transformation: Emotional Engagement in the Analytic Process. New Jersey: The Analytic Press.

Maroda, K. (2010). Psychodynamic Techniques: Working With Emotion in the Therapeutic Relationship. New York: Guilford Press.

Miller, A. (1979). Das Drama des begabten Kindes und die Suche nach dem wahren Selbst. Frankfurt am Main: Suhrkamp.

Mitchell, S. (1993). Hope and Dread in Psychoanalysis. New York: Basic Books.

Mitchell, S. (1997). Psychoanalyse als Dialog: Einfluss und Autonomie in der analytischen Beziehung. Giessen: Psychosozial Verlag.

Mitchell, S. (2000). Bindung und Beziehung: Auf dem Weg zu einer relationalen Psychoanalyse. Giessen: Psychosozial Verlag.

Mitchell, S. \& Aron, L. (Eds.) (1999). Relational Psychoanalysis: The Emergence of a Tradition. New Jersey: The Analytic Press.

Ogden, P. \& Fisher, J. (2015). Sensorimotor Psychotherapy: Interventions for Trauma and Attachment. New York: W. W. Norton.

Ogden, P., Minton, K. \& Pain, C. (2006). Trauma and the Body: A Sensorimotor Approach to Psychotherapy. New York: W. W. Norton. 
Ogden, T. (1995). Analyzing forms of aliveness and deadness of the transferencecountertransference. International Journal of Psychoanalysis, 76, 695-709.

Orange, D. (1995). Emotionales Verständnis und Intersubjektivität: Beiträge zu einer psychoanalytischen Epistemologie. Frankfurt am Main: Brandes \& Apsel.

Orange, D. (2010). Thinking for Clinicians: Philosophical Resources for Contemporary Psychoanalysis and the Humanistic Psychotherapies. New York: Routledge.

Orange, D. (2011). The Suffering Stranger: Hermeneutics for Everyday Clinical Practice. New York: Routledge.

Orange, D. (2016). Nourishing the Inner Life of Clinicians and Humanitarians: The Ethical Turn in Psychoanalysis. New York: Routledge.

Orange, D., Atwood, G. \& Stolorow, R. (1997). Intersubjektivität in der Psychoanalyse: Kontextualismus in der psychoanalytischen Praxis. Frankfurt am Main: Brandes \& Apsel.

Ornstein, P. (1995). Die Funktion der Theorie im Deutungsprozess. En P. Kutter, J. Paál, C. Schöttler, H.-P. Hartmann \& W. Milch (Eds.), Der therapeutische Prozess: Psychoanalytische Theorie und Methode in der Sicht der Selbstpsychologie (pp. 52-80). Frankfurt am Main: Suhrkamp.

Racker, H. (1960). Estudios sobre técnica psicoanalítica. Buenos Aires: Paidós.

Renik, O. (1993). Analytic interaction: Conceptualizing technique in light of the analyst's irreducible subjectivity. En S. Mitchell \& L. Aron (Eds.), Relational Psychoanalysis: The Emergence of a Tradition (pp. 407-424). New Jersey: The Analytic Press.

Renik, O. (2006). Practical Psychoanalysis for Therapists and Patients. New York: Other Press.

Ringstrom, P. (2007). Scenes that write themselves: Improvisational moments in relational psychoanalysis. Psychoanalytic Dialogues, 17 (1), 69-99.

Ringstrom, P. (2010). Meeting Mitchell's challenge: A comparison of relational psychoanalysis and intersubjective systems theory. Psychoanalytic Dialogues, 20 (2), 196-218.

Ringstrom, P. (2012). Principles of improvisation: A model of therapeutic play in relational psychoanalysis. En L. Aron \& A. Harris (Eds.), Relational Psychoanalysis: Evolution of Process (Vol. 5) (pp. 447-478). New York: Routledge.

Rodríguez Sutil, C. (2012). ¿Existe una técnica relacional? Clínica e Investigación Relacional, 6 (3), 515-527.

Safran, J. (2012). Psychoanalysis and Psychoanalytic Therapies. Washington: American Psychological Association.

Safran, J. \& Muran, C. (2000). La alianza terapéutica: Una guía para el tratamiento relacional. Bilbao: Desclée de Brouwer.

Sartre, J.-P. (1948). El existencialismo es un humanismo. Buenos Aires: Hyspamerica Ediciones.

Sassenfeld, A. (2010). Algunas reflexiones sobre la hermenéutica filosófica de Hans-Georg Gadamer y su relación con la práctica de la psicoterapia. Gaceta de Psiquiatría Universitaria, 6 (4), 427-448. 
Sassenfeld, A. (2012a). Principios clínicos de la psicoterapia relacional. Santiago de Chile: Ediciones SODEPSI.

Sassenfeld, A. (2012b). El desarrollo humano en la psicología analítica jungiana: Teoría e implicancias clínicas. Saarbrücken: Editorial Académica Española.

Sassenfeld, A. (2016). El espacio hermenéutico: Comprensión y espacialidad en la psicoterapia analítica intersubjetiva. Santiago de Chile: Ediciones SODEPSI.

Sassenfeld, A. (2017). La actitud hermenéutica como fundamentación y descripción filosófica de la actitud clínica de los psicoterapeutas analíticos intersubjetivos. Gaceta de Psiquiatría Universitaria, 13 (3), 272-286.

Sassenfeld, A. (2018). Los giros del psicoanálisis contemporáneo. Clínica e Investigación Relacional, $12(2), 268-317$.

Sassenfeld, A. (2019). Los giros del psicoanálisis contemporáneo: Una introducción al psicoanálisis relacional. Santiago de Chile: RIL Editores.

Schore, A. (2012). The Science of the Art of Psychotherapy. New York: W. W. Norton.

Seligman, S. (2018). Inaction and puzzlement as interaction: Keeping attention in mind. En L. Aron, S. Grand \& J. Slochower (Eds.), De-Idealizing Relational Theory: A Critique From Within (pp. 132149). New York: Routledge.

Siegel, D. (2012 [1999]). The Developing Mind: How Relationships and the Brain Interact to Shape Who We Are (2. Ed.). New York: The Guilford Press.

Slochower, J. (2014 [2006]). Psychoanalytic Collisions (2. Ed.). New York: Routledge.

Slochower, J. (2013). The analyst's secret delinquencies. Psychoanalytic Dialogues, 13, 451-469.

Slochower, J. (2018). Going too far: Relational heroines and relational excess. En L. Aron, S. Grand \& J. Slochower (Eds.), De-Idealizing Relational Theory: A Critique From Within (pp. 8-34). New York: Routledge.

Stern, D. B. (1997). Unformulated Experience: From Dissociation to Imagination in Psychoanalysis. New York: Psychology Press.

Stern, D. B. (2010). Partners in Thought: Working With Unformulated Experience, Dissociation, and Enactment. New York: Routledge.

Stern, D. B. (2015). Relational Freedom: Emergent Properties of the Interpersonal Field. New York: Routledge.

Stern, D. B. (2019). The Infinity of the Unsaid: Unformulated Experience, Language, and The Nonverbal. New York: Routledge.

Stern, D. N. (2004). The Present Moment in Psychotherapy and Everyday Life. New York: W. W. Norton.

Stern, D. N., Sander, L., Nahum, J., Harrison, A., Lyons-Ruth, K., Morgan, A., Bruschweiler-Stern, N. \& Tronick, E. (1998). Non-interpretive mechanisms in psychoanalytic therapy: The "something more" than interpretation. International Journal of Psychoanalysis, 79, 903-921. 
Stern, S. (2017). Needed Relationships and Psychoanalytic Healing: A Holistic Relational Perspective on the Therapeutic Process. New York: Routledge.

Stolorow, R. (2007). Trauma and Human Existence: Autobiographical, Psychoanalytic, and Philosophical Reflections. New York: The Analytic Press.

Stolorow, R. (2010). Un analista fenomenológico-contextual: La teoría de los sistemas intersubjetivos y la práctica clínica. Entrevista a Robert Stolorow. Gaceta de Psiquiatría Universitaria, 6 (3), 278-283.

Stolorow, R. \& Atwood, G. (2019). The Power of Phenomenology: Psychoanalytic and Philosophical Perspectives. New York: Routledge.

Stolorow, R., Atwood, G. \& Orange, D. (2002). Worlds of Experience: Interweaving Philosophical and Clinical Dimensions in Psychoanalysis. New York: Basic Books.

Stolorow, R., Brandchaft, B. \& Atwood, G. (1987). Psychoanalytische Behandlung: Ein intersubjektiver Ansatz. Frankfurt am Main: Fischer Taschenbuch Verlag.

Taylor, C. (1985). Self-interpreting animals. En C. Taylor, Philosophical Papers (Vol. 1) (pp. 45-76). Cambridge: Cambridge University Press.

Tublin, S. (2018). Core competency number one: Clinical intent. En R. Barsness (Ed.), Core Competencies of Relational Psychoanalysis: A Guide to Practice, Study, and Research (pp. 67-86). New York: Routledge.

Tylim, I. \& Harris, A. (Eds.) (2018). Reconsidering the Moveable Frame in Psychoanalysis: Its Function and Structure in Contemporary Psychoanalytic Theory. New York: Routledge.

Wachtel, P. (2014). Cyclical Psychodynamics and the Contextual Self: The Inner World, the Intimate World, and the World of Culture and Society. New York: Routledge.

Wallin, D. (2007). Attachment in Psychotherapy. New York: The Guilford Press.

Wolf, E. (1988). Theorie und Praxis der psychoanalytischen Selbstpsychologie. Frankfurt am Main: Suhrkamp.

Original recibido con fecha: 17/7/2019 Revisado: 30/10/2019 Aceptado: 30/10/2019

NOTAS:

\footnotetext{
${ }^{1}$ Para una descripción detallada de los conceptos de teoría, técnica y práctica en relación con el psicoanálisis, véanse Orange, Atwood y Stolorow (1997) y Sassenfeld (2012a, 2016).

${ }^{2}$ Para algunos aspectos de la relación entre Freud y Descartes, véanse Cavell (1993) y Stolorow y Atwood (2019).

${ }^{3}$ Se mostraría probablemente en desacuerdo aquel supervisor clásico mencionado por Stolorow, Atwood y Orange (2002), para quien a un psicoanalista de gran experiencia ya nada lo puede sorprender. En contraste con Stern, Mark Leffert (2016) asevera que la provisionalidad y ausencia de certidumbre que figura de forma explícita en diversos escritos de Freud se perdió por completo en la literatura psicoanalítica clásica posterior, que en su opinión adopta un tono marcado por la certidumbre. Agrega: "Mi propia experiencia con tres diferentes analistas y varios supervisores en la década de 1970 y los inicios de la década de 1980 fue que nunca me encontré con duda o incertidumbre en nada de lo que me dijeron" (p. 95).
} 
${ }^{4}$ Admito que la categoría de lo razonable es compleja y de difícil definición; sin embargo, esa complejidad me parece inherente a todo intento de acercarse a entender lo que significa la noción de phronesis entendida como sensatez y prudencia. Aunque no puedo entrar en este punto aquí, sí quiero afirmar que en mi opinión nos adentramos en el terreno de los consensos intersubjetivos entre quienes llevan a cabo una cierta práctica, tal como subrayan Richard Bernstein (1983) y también Jürgen Habermas -con independencia de las simultáneas posibilidades y limitaciones inherentes a los consensos intersubjetivos. Para algunas ideas respecto de lo razonable, véase Sassenfeld (2016). 